\title{
Results of Coronary Artery Bypass Grafting Alone Versus Combined Surgical Revascularization and Mitral Repair In Patients with Moderate Ischemic Mitral Regurgitation
}

\author{
Ahmed Khallaf, ${ }^{1}$ Mahmoud Elzayadi, ${ }^{1}$ Hesham Alkady, ${ }^{2}$ Ahmed Elnaggar ${ }^{2}$ \\ ${ }^{1}$ Department of Cardiothoracic Surgery, Fayoum University, Fayoum, Egypt; ${ }^{2}$ Department of Cardiothoracic Surgery, Cairo \\ University, Egypt
}

\section{ABSTRACT}

Background: This is a prospective randomized-controlled study done to evaluate the best surgical option for moderate ischemic mitral regurgitation through either coronary artery bypass grafting only or by performing additional mitral repair.

Methods: Over a nine-month period, 60 patients with ischemic heart disease associated with moderate ischemic mitral regurgitation were equally divided into two groups. Group 1 included 30 patients who had coronary artery bypass grafting with mitral valve repair; Group 2 included 30 patients who had only coronary artery bypass grafting.

Results: There were no significant differences between the study groups, regarding operative data, apart from the cardiopulmonary bypass time and aortic cross-clamp time, which were significantly longer in group $1(\mathrm{P}<0.001)$. Only one patient died in group 1 due to severe myocardial dysfunction. During the follow up, the NYHA class improved in group 1, from 2.7 to 1.35 ( $\mathrm{P}<0.004)$, compared with group 2, where the NYHA class improved from 2.6 to $1.72(\mathrm{P}=0.07)$. The degree of MR improved in 28 patients (93\%) in group 1 and 22 patients $(73 \%)$ in group $2(\mathrm{P}<0.0001)$.

Conclusion: The study revealed many advantages of adding mitral repair to surgical revascularization in patients with moderate ischemic mitral regurgitation, with improvement in the degree of MR and NYHA functional class. On the other hand there were no significant differences between the groups, regarding the postoperative course and incidence of mortality.

\section{INTRODUCTION}

Ischemic mitral regurgitation is defined as mitral regurgitation resulting from myocardial infarction (MI) or ischemic heart disease, without structural damage to the subvalvular mitral apparatus [Gorman 2003]. Valvular incompetence in this case is due to papillary muscle (PM) displacement, leaflet shortening, and dilatation of the mitral annulus [Kumanohoso 2003].

Received October 14, 2019; accepted March 10, 2020.

Correspondence: Abmed Khallaf, Department of Cardiotboracic Surgery, Fayoum University, Fayoum, Egypt (e-mail: ankballaf@gmail.com).
There is no debate in general on the fact that severe (grades $3+$ to $4+$ ) chronic ischemic mitral regurgitation (CIMR) should be addressed by valve repair in conjunction with coronary artery bypass grafting (CABG), whereas mild (grade 1+) CIMR does not warrant intervention. Meanwhile, the optimal management of moderate (grade 2+) CIMR still is debatable [Fattouch 2009]. This controversy is partly due to the lack of data from larger studies to determine whether the advantages of concomitant mitral repair (MVR) and CABG would worth the risks of this complex and lengthy procedure or not [El Bardissi 2012; Lee 2011]. The argument of the authors favoring surgical revascularization alone for the management of ischemic mitral regurgitation is that restoring the blood supply to the ischemic myocardium will improve the $\mathrm{LV}$ function and consequently reduce its size, improve papillary muscle function as well as the integrity of the subvalvular apparatus [Penicka 2009; Roshanali 2006].

Supporters of combined mitral repair and CABG seriously consider the adverse effects of persistent ischemic mitral regurgitation and additionally argue that in patients with poor LV function, mitral valve repair has the advantages of preventing progressive adverse remodeling, improving the myocardial function, and decreasing the incidence of heart failure [Flynn 2009; Bax 2004].

\section{PATIENTS AND METHODS}

This prospective randomized-controlled study was done at the Cairo University Hospital between March to December 2014. The study included 60 ischemic patients with a moderate degree of ischemic mitral regurgitation (IMR) who were candidates for CABG surgery. Moderate IMR was confirmed by transesophageal echocardiography (TEE). Excluded from our study were patients with a mild or severe degree of IMR, MR not of ischemic origin (rheumatic), other valve diseases warranting intervention, associated left ventricular aneurysm or ischemic VSD, and previous open heart surgeries (redo cases) as well as off-pump cases. Patients were divided into two groups of 30 patients each, using propensity scores according to patient characteristics. Group 1 patients were assigned for on-pump CABG and mitral repair; Group 2 patients were to have only on-pump CABG. The diagnosis and severity of IHD were assessed by 
Table 1. Demographic and clinical data

\begin{tabular}{lccc}
\hline & Group 1 (CABG \& repair) $(\mathrm{N}=30)$ & Group 2 (CABG) $(\mathrm{N}=30)$ & \\
\hline Age (years) & $55.3 \pm 5.9$ & $54.8 \pm 5.1$ & $18(60 \%)$ \\
Male & $17(55 \%)$ & $12(40 \%)$ & 0.9 \\
Female & $13(45 \%)$ & $17(55 \%)$ & 0.8 \\
Diabetes & $18(60 \%)$ & $13(45 \%)$ & 0.8 \\
Hypertension & $18(60 \%)$ & $18(60 \%)$ & 0.8 \\
Previous infarction & $20(65 \%)$ & 2.6 & 0.6 \\
NYHA class & 2.7 & $5(15 \%)$ & 0.8 \\
Two-vessel disease & $6(20 \%)$ & $23(75 \%)$ & 0.8 \\
Three-vessel disease & $21(70 \%)$ & $2(8 \%)$ & 0.71 \\
Four-disease vessel & $3(10 \%)$ & $4.1 \pm 0.6$ & 0.71 \\
Left atrium & $4.3 \pm 0.32$ & $0.50 \pm 0.04$ & 0.06 \\
Ejection fraction $(\%)$ & $0.48 \pm 0.06$ & $4.43 \pm 0.35$ & 0.16 \\
Left ventricular ESD $(\mathrm{cm})$ & $4.39 \pm 0.41$ & $5.7 \pm 0.44$ & 0.60 \\
Left ventricular EDD $(\mathrm{cm})$ & $6.1 \pm 0.43$ & 0.41 \\
\hline
\end{tabular}

coronary angiography in all patients. Moderate mitral regurgitation was defined as the presence of at least two of the three following criteria: 1) A regurgitant orifice area (ERO) of 0.2 to $0.4 \mathrm{~cm} 2$; 2) A vena contracta width of 3 to $7 \mathrm{~mm}$; 3) A mitral regurgitation jet area of $20 \%$ to $40 \%$ of the left atrium. Supportive criteria included the size of the chamber, jet eccentricity, and pulmonary-vein Doppler flow pattern. This study was approved by the ethical committee and informed consents were obtained from all patients, concerning both the operation and enrollment in the study. Patient demographics and preoperative clinical data are presented in Table 1. There were no statistically significant differences, regarding the preoperative demographic, clinical and echocardiographic criteria between the groups.

Intraoperative time parameters as well as surgical procedures were noted. Similarly, postoperative data were recorded, including ICU course, postoperative complications, in-hospital mortality, echocardiographic outcomes (left ventricular end-systolic diameter (LVESD), left ventricular end-diastolic diameter (LVEDD), and left ventricular ejection fraction (LVEF) as a measure of left ventricular remodeling as well as the degree of residual MR and regional wall motion abnormalities (RWMA). Also recorded were the Canadian Cardiovascular Society (CCS) class for heart failure and angina and the New York Heart Association (NYHA) functional class, as a measure of clinical status of patients. Patients were followed up at our outpatient clinic both clinically and through echocardiography three months after surgery as well as at intervals of six months. (Table 1)

Statistical analysis: Data was analyzed using SPSS software (version 18, IBM). Quantitative data were expressed using mean \pm standard deviation, median, while categorical data were presented as frequency (count) and relative frequency (percentage). For comparison between quantitative parametric data, student $\mathrm{t}$-Test was used and for qualitative data, Chi square and $\mathrm{McNemar}$ tests were used. $\mathrm{P}$ value $\leq 0.05$ was considered as the cut-off value for significance.

Surgical technique: All surgical procedures were performed through a median sternotomy on normothermic cardiopulmonary bypass $(\mathrm{CPB})$ with intermittent antegrade warm blood cardioplegia delivered to the aortic root. All patients had conventional CABG surgery using the left internal mammary artery (LIMA) to graft the left anterior descending (LAD) coronary, and saphenous vein grafts for other coronary arteries. For patients assigned concomitant CABG and mitral repair, a left atriotomy was done to access the mitral valve. Mitral annuloplasty was done using a Carpentier-Edwards ring. Sizing was done, according to the length of the anterior mitral leaflet or intertrigonal distance, with some downsizing to reduce the annular dilatation. Data are listed in Table 2.

\section{RESULTS}

Operative data: There were no statistically significant differences between the two study groups, regarding the operative data apart from the $\mathrm{CPB}$ and cross-clamp times, which were significantly longer in group 1, with a median CPB time of 90 minutes versus 57.42 minutes and a median crossclamp time of 73.8 minutes versus 43.7 minutes in group 2, respectively. These differences can be explained by the more complex procedure in group 1 , and the extra time needed for the additional mitral repair $(\mathrm{P}<0.001)$. Twenty-four patients $(80 \%)$ in group 1 and 23 patients $(75 \%)$ in group 
Table 2. Perioperative data

\begin{tabular}{|c|c|c|c|}
\hline & Group $1(N=30)$ Mean & Group $2(N=30)$ Mean & $P$ \\
\hline Bypass time (min) & $90 \pm 10.2$ & $57.42 \pm 8.7$ & $<.001$ \\
\hline Cross-clamp time (min) & $73.8 \pm 7.9$ & $43.7 \pm 8.8$ & $<.001$ \\
\hline Number of grafts & $2.8 \pm 0.45$ & $2.8 \pm 0.49$ & 0.9 \\
\hline Inotropic support & $12(40 \%)$ & $18(60 \%)$ & 0.4 \\
\hline $\mathrm{IABP}$ & 1 & 0 & \\
\hline Mechanical ventilation (hrs) & $6.3 \pm 1.6$ & $7.4 \pm 1.9$ & .07 \\
\hline ICU stay (days) & $2.6 \pm 0.58$ & $3.2 \pm 0.84$ & .07 \\
\hline Hospital stay (days) & $10.55 \pm 1.34$ & $10.35 \pm 1.24$ & 0.6 \\
\hline LCOS & $1(3 \%))$ & $0(0 \%)$ & 0.2 \\
\hline Exploration & $1(3 \%)$ & $0(0 \%)$ & 0.2 \\
\hline In-hospital mortality & $1(3 \%)$ & $0(0 \%)$ & 0.2 \\
\hline
\end{tabular}

LCOS: Low cardiac output syndrome.

2 had venous grafts on the right coronary artery (RCA) or posterior descending artery (PDA). Weaning from cardiopulmonary bypass went smoothly in 18 patients $(60 \%)$ of group 1 and 12 patients (40\%) in group 2. The remaining patients needed additional inotropic support and one patient in group 1 needed intra-aortic balloon pump counterpulsation for support as shown in Table 2.

Postoperative data: Patients were discharged to the intensive care unit (ICU) on mechanical ventilation. Postoperative management was according to our standard protocol. Patients were discharged from the ICU with stable hemodynamics without inotropes, with no drains, with acceptable laboratory investigations, and without ischemic changes or arrhythmias in the ECG. Table 3 shows the postoperative parameters. As shown, all the differences were statistically insignificant. Postoperative bleeding occurred in only one patient in group 1, and reexploration revealed bleeding at the sternal wire sites, which was controlled. There was another case from the same group with postoperative low cardiac output syndrome. There was a single mortality in group 1 on the third postoperative day, due to severe low cardiac output without any response to inotropes and IABP counterpulsation, despite the absence of any evidence of perioperative infarction.

Follow-up data: Patients could be followed up for a mean period of $4 \pm 1.3$ years after discharge. Follow up was complete in 59 patients in both groups. Only one patient skipped follow up, due to loss of updated contact data. No mortality was detected in patients, during follow up. Also, NYHA class in group 1 improved from 2.7 to $1.35(\mathrm{P}<0.004)$, whereas in group 2 it improved from 2.6 to $1.72(\mathrm{P}=0.07)$. NYHA class II or above was detected in $12(40 \%)$ patients in group 1 . This was statistically significant in relation to the preoperative data $(\mathrm{P}=0.004)$. In group 2 , it was found in $21(70 \%)$ patients, which was statistically insignificant $(\mathrm{P}=0.07)$.

Improvement of the degree of mitral regurgitation occurred in 28 patients $(93 \%)$ in group 1 versus $22(73 \%)$ patients in the group $2(\mathrm{P}<0.0001)$. In group 1 , mitral regurgitation was absent postoperatively in 21 patients and improved to grade $1+$ in seven patients. In group 2 , the degree of mitral regurgitation was grade $1+$ in 22 patients, grade $2+$ with no improvement in six patients, and worsened to grade $3+$ in only one patient. These differences were significant $(\mathrm{P}<0.001)$. These results show that with CABG only, $20 \%$ of patients were left with moderate mitral regurgitation, and moreover, that the degree of regurgitation increased in one case, from moderate to severe.

Otherwise, the difference between other pre- and postoperative echo findings during follow up was statistically insignificant with $\mathrm{P}>0.05$. Table 3 summarizes the follow-up data.

\section{DISCUSSION}

Evidence from multiple studies suggest that CIMR is directly related to a poorer prognosis and higher mortality in CABG patients. This is due to its presence rather than the degree of mitral regurgitation. Evaluating, however the degree of mitral regurgitation under resting conditions can underestimate its outcome. Indeed, ischemic mitral regurgitation is a changing process, and its severity can change with time [Grigioni 2001; Aklog 2001; Hickey 1988; Di Mauro 2006]. Clinical trials have led to much controversy, regarding the proper management of moderate mitral regurgitation during CABG. This debatable decision is mainly due to the lack of large prospective studies and to the comparison of results in unmatched patient groups [Fattouch 2009].

Surgeons advocating only CABG believe the degree of mitral regurgitation is due to papillary muscle dysfunction, which can improve after myocardial revascularization. These authors suggest that revascularization alone leads to improvement of left ventricular dyskinesia, a reduction in the volume of the left ventricle, and finally, a significant improvement of 
Table 3. Follow-up data

\begin{tabular}{|c|c|c|c|c|c|c|}
\hline Ejection fraction \% & $0.48 \pm 0.06$ & $0.54 \pm 0.1$ & 0.08 & $0.50 \pm 0.04$ & $0.54 \pm 0.6$ & 0.14 \\
\hline LVESD & $4.39 \pm 0.41$ & $4.20 \pm 0.42$ & 0.12 & $4.43 \pm 0.35$ & $4.12 \pm 0.8$ & 0.09 \\
\hline NYHA class (mean) & 2.7 & 1.35 & 0.003 & 2.6 & 1.72 & 0.06 \\
\hline Mitral regurgitation & 2 & 0.27 & - & 2 & 1.4 & 0.6 \\
\hline
\end{tabular}

ESD: End systolic diameter, EDD: End diastolic diameter

the degree of mitral regurgitation because of a restoration of the valvular function [Lee 2011; Penicka 2009]. Our study suggests that these facts are not accurate because with myocardial scarring and fibrosis following myocardial infarction, revascularization alone will not be sufficient to improve the myocardial function. Moreover, remodeling of the left ventricle wouldn't be maintained, and the reverse remodeling postoperatively would be unpredictable. Therefore, we studied the outcomes of moderate ischemic mitral regurgitation after isolated CABG, comparing it with combined CABG and mitral repair, during the early and midterm follow up.

There were no statistically significant differences between the two study groups regarding age, gender, risk factors for IHD, clinical condition, and preoperative investigations. However, there was something to be noted in the preoperative evaluation. Sixty-five percent of the patients in group 1 had a previous inferior infarction versus $60 \%$ of the patients in group 2. This confirms the data mentioned by other studies stating that, although the incidence of anterior infarction is more common, the development of mitral regurgitation is more common after a posterior-inferior infarction [Kumanohoso 2003]. Calafiore and colleagues, in a study done on 102 patients with ischemic mitral regurgitation, noted that the incidence of a posterior-inferior infarction was $61.3 \%$. This is anatomically due to the fact that the posterior papillary muscle has only one segmental arterial supply and therefore when blocked, the papillary muscle infarction leads to retraction of the posterior mitral leaflet causing mitral regurgitation [Calafiore 2004].

The postoperative course as well as the in-hospital mortality for both groups in our series showed no statistically significant difference. Fattouch et al. had similar results [Fattouch 2009]. However, in other series, the longer bypass time and more complicated surgery in the CABG and MVR group, due to the need for an extra atriotomy and the performance of valve annuloplasty, were associated with a more complicated postoperative course [Tolis 2002; Kim 2005; Kang 2006; Ryden 2001; Duarte 1999]. This might not have been evident in our study, due to the relatively small cohort. On the other hand, the benefit of adding mitral repair to the
CABG surgery was evidenced clinically by the improvement of the NYHA functional class and by the decrease of the echocardiographic grade of mitral regurgitation postoperatively. There is much controversy in the literature regarding these results. Fattouch and colleagues in their study enrolled 102 patients for CABG only or CABG with mitral repair with an average follow up of 32 months. They concluded that the left ventricular function, grade of mitral regurgitation, and NYHA class all improved with concomitant CABG and valve repair, when compared with revascularization only [Fattouch 2009]. An improvement in the degree of mitral regurgitation was similarly reported by other studies [Kang 2006; Ryden 2001; Wong 2005; Mallidi 2004].

On the contrary, Kim et al. observed no significant improvement in the NYHA functional class at 2 years between only revascularization (from $3.12 \pm 1$ to $1.12 \pm 0.38$ ) and revascularization with mitral repair (from $3.22 \pm 0.82$ to $1.29 \pm 0.63$ ) [Kim 2005]. We believe that the discrepancy between our results and other studies may be related to the differences in the end points studied, the estimation of the degree of mitral regurgitation, the time frame between the initial diagnosis of ischemic mitral regurgitation and the study enrollment, and the incidence of new myocardial infarctions either due to disease progression or graft failure. Campwala et al. found in their study that failure of the graft of the posterior descending coronary is an independent predictor of postoperative ischemic mitral regurgitation degree [Campwala 2006]. In a study done by Lam et al., follow-up echo was only done for 156 out of 467 patients. Therefore, some of these echocardiograms may have been driven by patient complaints or the presence of a murmur during physical examination. This would cause overestimation of patients with increasing the severity of mitral regurgitation [Lam 2005]. The study by Aklog et al. described moderate IMR as grade $3+$, whereas in most studies, including ours, moderate degree is defined as grade $2+$. Thus, it should be noted that these authors enrolled patients with a more severe degree of ischemic mitral regurgitation [Aklog 2001].

\section{CONCLUSION}


Our study showed meaningful advantages of adding mitral annuloplasty to CABG in patients with IHD and moderate mitral regurgitation regarding the degree of $M R$ and functional NYHA class. On the other hand, there was no statistically significant difference between the groups in postoperative course and in-hospital mortality.

\section{REFERENCES}

Aklog L, Filsoufi F, Flores KQ, et al. 2001. Does coronary artery bypass grafting alone correct moderate ischaemic mitral regurgitation? Circulation 104:68-75.

Bax JJ, Braun J, Somer ST, et al. 2004. Restrictive annuloplasty and coronary revascularization in ischemic mitral regurgitation results in reverse left ventricular remodeling. Circulation 110:103.

Calafiore AM, Di Mauro M, Gallina S, Di Giammarco G, Iacò AL, Teodori G, Tavarozzi I. 2004. Mitral valve surgery for chronic ischemic mitral regurgitation. Ann Thorac Surg 77:1989-1997.

Campwala ZC, Bansal RC, Wang N, Razzouk A, Pai RG, et al. 2006. Mitral regurgitation progression following isolated coronary artery bypass surgery: frequency, risk factors, and potential prevention strategies. Eur J Cardiothorac Surg 29:348-354.

Di Mauro M, Di Giammarco G, Vitolla G, Contini M, Iaco AL, Bivona A, et al. 2006. Impact of no-to-moderate mitral regurgitation on late results after isolated coronary artery bypass grafting in patients with ischemic cardiomyopathy. Ann Thoracic Surg 81:2128-34.

Duarte IG, Shen Y, MacDonald MJ, Jones EL, Craver JM, Guyton RA. 1999. Treatment of moderate mitral regurgitation and coronary disease by coronary bypass alone: late results. Ann Thoracic Surg. 68:426-30.

El Bardissi AW, Aranki SF, Sheng S, O'Brien SM, Greenberg CC, Gammie JS. 2012. Trends in isolated coronary artery bypass grafting: an analysis of the Society of Thoracic Surgeons adult cardiac surgery database. J Thorac Cardiovasc Surg 143:273-281.

Fattouch K, Guccione F, Sampognaro R, Panzarella G, Corrado E, Navarra E, Calvaruso D, Ruvolo G. 2009. Impact of Moderate Ischemic Mitral Regurgitation After Isolated Coronary Artery Bypass Grafting, J. of Thoracic and Cardiovascular Surgery 138:278-285.

Fattouch K, Guccione F, Sampognaro R, Panzarella G, Corrado E, Navarra E, Calvaruso D, Ruvolo G. 2009. POINT: Efficacy of adding mitral valve restrictive annuloplasty to coronary artery bypass grafting in patients with moderate ischemic mitral valve regurgitation: a randomized trial. J Thorac Cardiovasc Surg 138:278-285.

Flynn M, Curtin R, Nowicki ER, et al. 2009. Regional wall motion abnormalities and scarring in severe functional ischemic mitral regurgitation: a pilot cardiovascular magnetic resonance imaging study. J Thorac Cardiovasc Surg. 137:1063-1070.
Gorman RC, Gorman JH, 3rd, Edmunds LH Jr. 2003. Ischemic mitral regurgitation. In: Cohn LH, Edmunds LH Jr., editors. Cardiac surgery in the adult. New York: McGraw-Hill 51-769.

Grigioni F, Enriquez-Sarano M, Zehr KJ, Bailey KR, Tajik AJ. 2001. Ischemic mitral regurgitation. Long-term outcome and prognostic implications with quantitative Doppler assessment. Circulation 103:1759-1764.

Hickey MS, Smith LR, Muhlbaier LH, Harrell FE Jr, Reves JG, Hinohara T, et al. 1988. Current prognosis of ischemic mitral regurgitation. Circulation. 78:I51-9.

Kang DH, Kim MJ, Kang SJ, et al. 2006. Mitral valve repair versus revascularization alone in the treatment of ischemic mitral regurgitation. Circulation 114:499.

Kim YH, Czer LS, Soukiasian HJ, De Robertis M, Magliato KE, Blanche C, Raissi SS, Mirocha J, Siegel RJ, Kass RM, et al. 2005. Ischemic mitral regurgitation: revascularization alone versus revascularization and mitral valve repair. Ann Thorac Surg 79:1895-1901.

Kumanohoso T, Otsuji Y, Yoshifuku S, Matsukida K, Koriyama C, Kisanuki A, Minagoe S, Levine RA, Tei C. 2003. Mechanism of higher incidence of ischemic mitral regurgitation in patients with inferior myocardial infarction: quantitative analysis of left ventricular and mitral valve geometry in 103 patients with prior myocardial infarction. J Thorac Cardiovasc Surg 125:135-143.

Lam BK, Gillinov AM, Blackstone EH, et al. 2005. Importance of moderate ischemic mitral regurgitation. Ann Thorac Surg 79:462-470.

Lee R, Li S, Rankin JS, et al. 2011. Fifteen-year outcome trends for valve surgery in North America. Ann Thorac Surg 91:677-684.

Mallidi HR, Pelletier MP, Lamb J, et al. 2004. Late outcomes in patients with uncorrected mild to moderate mitral regurgitation at the time of isolated coronary artery bypass grafting. J Thorac Cardiovasc Surg 127:636-644.

Penicka M, Linkova H, Lang O, et al. 2009. Predictors of improvement of unrepaired moderate ischemic mitral regurgitation in patients undergoing elective isolated coronary artery bypass graft surgery. Circulation 120:1474-1481.

Roshanali F, Mandegar MH, Yousefnia MA, Alaeddini F, Wann S. 2006. Low-dose dobutamine stress echocardiography to predict reversibility of mitral regurgitation with CABG. Echocardiography 23:31-37.

Ryden T, Bech-Hanssen O, Brandrup-Wognsen G, et al. 2001. The importance of grade 2 ischaemic mitral regurgitation in coronary artery bypass grafting. Eur J Cardiothorac Surg 20:276-81.

Tolis GA Jr, Korkolis DP, Kopf GS, et al. 2002. Revascularization alone (without mitral valve repair) suffices in patients with advanced ischaemic cardiomyopathy and mild-to-moderate mitral regurgitation. Ann Thorac Surg 74: 1476-80.

Wong DR, Agnihotri AK, Hung JW, et al. 2005. Long-term survival after surgical revascularization for moderate ischemic mitral regurgitation. Ann Thorac Surg 80:570-577. 